\title{
Sinus of Valsalva-right atrial tunnel causing heart failure in a 38-year-old
}

\author{
Sophia L. Dellis, MD, ${ }^{\mathrm{a}}$ Timothy Pennel, MBChB, PhD, ${ }^{\mathrm{b}}$ Qonita Said-Hartley, MBChB, ${ }^{\mathrm{c}}$ and \\ Peter Zilla, MD, PhD, ${ }^{b}$ Albany, NY, and Cape Town, South Africa
}

\author{
From the ${ }^{\mathrm{a}}$ Division of Cardiothoracic Surgery, Albany Medical Center, Albany, NY; and ${ }^{\mathrm{b}}$ Chris Barnard Division \\ of Cardiothoracic Surgery, and ${ }^{\mathrm{c}}$ Department of Radiology, Groote Schuur Hospital, Cape Town, South Africa. \\ Disclosures: Authors have nothing to disclose with regard to commercial support. \\ Received for publication March 19, 2017; revisions received May 16, 2017; accepted for publication June 3, 2017 ; \\ available ahead of print June 30, 2017 \\ Address for reprints: Sophia L. Dellis, MD, Division of Cardiothoracic Surgery, Albany Medical Center, 47 New \\ Scotland Ave, MC 192, Albany, NY 12208 (E-mail: sophialdellis@gmail.com). \\ J Thorac Cardiovasc Surg 2018;155:e51-3 \\ $0022-5223 / \$ 36.00$ \\ Copyright (c) 2017 by The American Association for Thoracic Surgery \\ http://dx.doi.org/10.1016/j.jtcvs.2017.06.005
}

Video clip is available online.

Sinus of Valsalva-right atrial fistulas are rare and may have infectious, iatrogenic, or congenital etiologies. We present a patient who developed heart failure due to a left coronary sinus of Valsalva-right atrial tunnel.

\section{CLINICAL SUMMARY}

The patient is a 38-year-old woman with a history of dyspnea, orthopnea, gastroesophageal reflux disease, and hypertension controlled with atenolol and amlodipine who was admitted to the hospital in class III heart failure. She had been admitted to an outside hospital 20 months previously with episodes of atypical chest pain that lasted approximately 5 minutes and were usually preceded by palpitations.

On physical examination, she had a 3/6 systolic ejection murmur and a 2/6 diastolic murmur at the right upper sternal border. Her point of maximum impulse was displaced in the left fifth intercostal space. She had no peripheral edema or jugular venous distension.

Electrocardiogram showed normal sinus rhythm, and echocardiogram showed left ventricular hypertrophy with an ejection fraction of $52 \%$. She had trace aortic insufficiency with a peak gradient of $27.5 \mathrm{~mm} \mathrm{Hg}$ and a peak velocity of $2.09 \mathrm{~m} / \mathrm{s}$. A computed tomography scan further clarified the aortoatrial communication (Figures 1 and 2).

The patient was electively taken to the operating room for fistula closure. She was prepped and draped in the usual sterile fashion. A median sternotomy was performed, and she was placed on cardiopulmonary bypass with aortobicaval cannulation. She was cooled to $28^{\circ} \mathrm{C}$. The aorta was crossclamped, and the heart was arrested with cold cardioplegia.

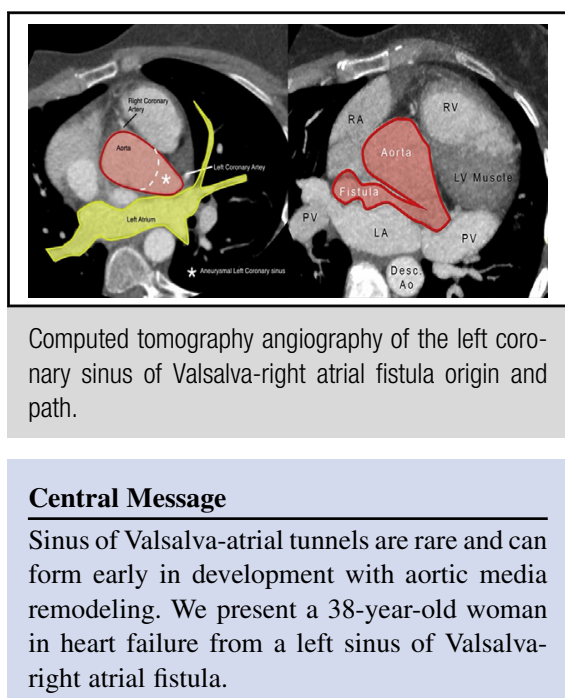

See Editorial Commentaries pages e55 and e57.

retrograde and anterograde St Thomas/Lignocaine blood

Cardiac anatomy was inspected; a tunnel was found originating centrally in the left coronary sinus of Valsalva inferior to the sinotubular junction. It traveled posterior to the ascending aorta and superior vena cava before emptying into the right superolateral aspect of the right atrium (Video 1).

The patent ductus arteriosus was ligated, and an aortotomy was performed that unveiled 2 left coronary ostia (one minute and the other sizeable) and one right coronary ostium. The right atriotomy that followed confirmed the opening of the sinus tract into the right atrium. The left sinus of Valsalva fistula opening was closed with polypropylene suture, and the atrial opening was ligated with pledgeted polypropylene.

After closure of the aortotomy and atriotomy, the patient was rewarmed, the heart de-aired, and the crossclamp removed (crossclamp time 58 minutes). The heart resumed in sinus rhythm, and the patient was weaned off bypass (cardiopulmonary bypass time 103 minutes). Hemostasis was achieved, the chest was closed, and the patient was transferred to the intensive care unit in stable condition with 2 temporary pacing wires.

The patient spent 39 hours in the intensive care unit and was discharged on postoperative day 8 without any 


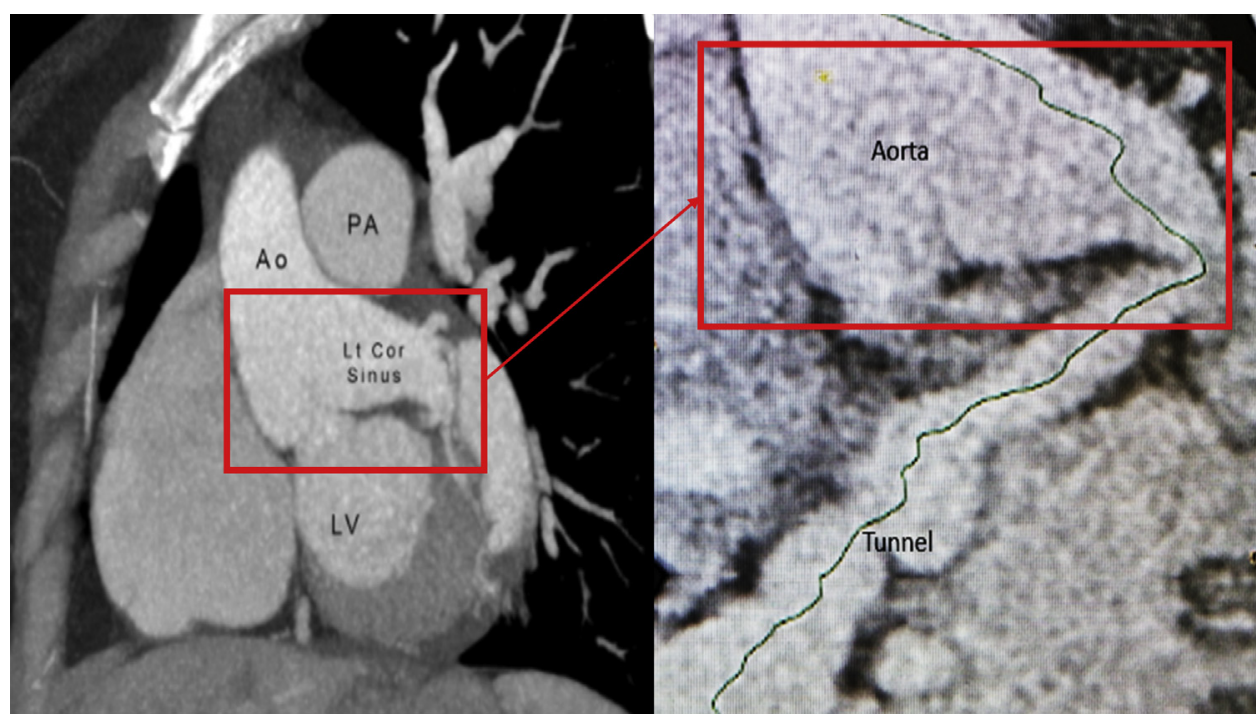

FIGURE 1. Computed tomography angiography showing the aneurysmal left coronary sinus and tunnel tracked with vessel extraction software. Ao, Aorta; $P A$, pulmonary artery; $L V$, left ventricle.

postoperative complications. At 1-week follow-up, she was recovering well.

\section{DISCUSSION}

There are limited data on aortoatrial tunnels, as they are rare. Incidence of isolated sinus of Valsalva aneurysms in cardiac surgery have been reported to be from $0.14 \%$ to $0.96 \% .{ }^{1}$ However, aortoatrial tunnels, sinus of Valsalva aneurysms, and coronary-cameral fistulas are not synonymous.

Tunnels travel anteriorly or posteriorly and end in the atrium, whereas sinus of Valsalva aneurysms originate inferior to the sinotubular ridge and may have intracardiac rupture; coronary-cameral fistulas have a coronary emptying aberrantly into a chamber. ${ }^{2,3}$

With lack of evidence for an acquired cause, it is likely that this patient's aortoatrial tunnel was congenital with pathology of the media of the distal bulbar septum. ${ }^{1}$ The systemic pressure of the aorta on weak elastic lamina probably created the tunnel. This explains why anterior tunnels tend to originate from the right coronary sinus and posterior tunnels tend to stem from the left coronary sinus. ${ }^{4}$

Because of her extensive symptoms, the fistula size, and the fact that natural progression could lead to the need for

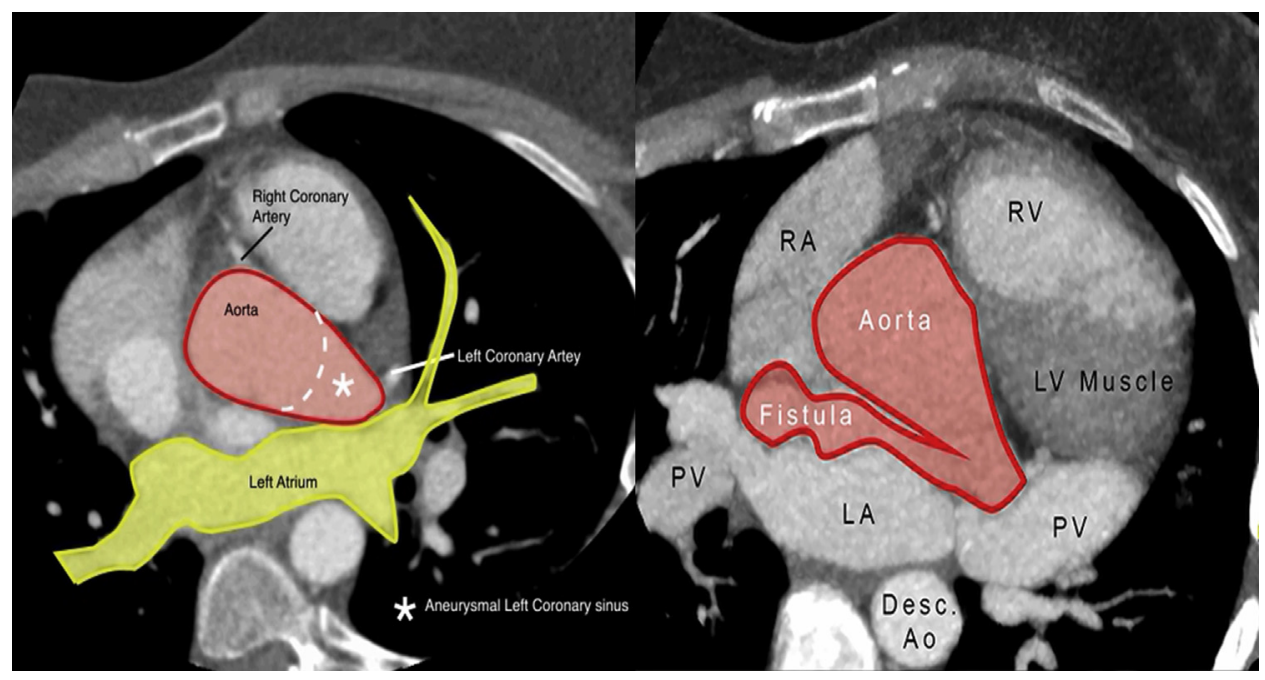

FIGURE 2. Computed tomography angiography of the left coronary sinus of Valsalva-right atrial fistula origin and path. $R A$, Right atrium; $R V$, right ventricule; $L V$, left ventricle; $P V$, pulmonary vein; $L A$, left atrium; Desc. Ao, descending thoracic aorta. 


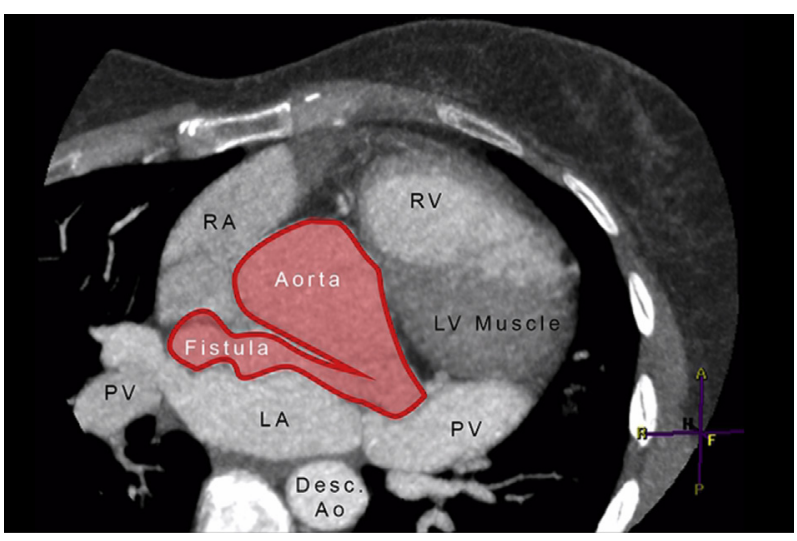

VIDEO 1. Description of the patient's unique cardiac tunnel anatomy. Video available at: http://www.jtcvsonline.org/article/S0022-5223(17) 31172-8/addons.

aortic valve replacement and more complex surgery, the decision was made to surgically versus percutaneously close the fistula.

Surgical closure of a tunnel is a relatively safe long-term solution. In a study of 129 patients, Takach and colleagues ${ }^{1}$ found that the 5 in-hospital deaths in sinus of Valsalva aneurysms/fistula patients were related to septic endocarditis or Marfan syndrome. The other long-term complications that occurred were attributable to prosthetic valve placement, which this patient did not have, or anticoagulation.

Given this patient's development of heart failure at a young age and the size of her aortoatrial tunnel, she had no option but to undergo surgical correction of her left coronary sinus of Valsalva-right atrial fistula. Because she had a competent aortic valve and no evidence of myocardial ischemia, her valve and anomalous coronaries remained untouched.

\section{References}

1. Takach TJ, Reul GJ, Duncan JM, Cooley DA, Livesay JJ, Ott DA, et al. Sinus of Valsalva aneurysm or fistula: management and outcome. Ann Thorac Surg. 1999; 68:1573-7.

2. Sai Krishna C, Baruah DK, Reddy GV, Panigrahi NK, Suman K, Kumar PV. Aortaright atrial tunnel. Tex Heart Inst J. 2010;37:480-2.

3. Subban V, Sankardas MA, Janakiraman E. Left aortic sinus to right atrial tunnel. Eur Heart J. 2010;31:164.

4. Gajjar T, Voleti C, Matta R, Iyer R, Kumar Dash P, Desai N. Aorta-right atrial tunnel: clinical presentation, diagnostic criteria, and surgical options. J Thorac Cardiovasc Surg. 2005;130:1287-92 